consult their partners before having an HIV test. Availability and accessibility of PMTCT service facilities, associated stigma, shame and fear, confidentiality of reports and concerns over risk to the foetus due to lack of knowledge are some of the potential barriers identified with future PMTCT programs.

Conclusion Lack of knowledge, stigma and fear and confidentiality issues need to be overcome with extensive universal awareness programs on HIV/AIDS and PMTCT.

\section{P075 DISCRIMINATORY ATTITUDES TOWARDS PEOPLE LIVING WITH HIVIAIDS, A POPULATION BASED STUDY IN SRI LANKA}

${ }^{1,2}$ A.A.I.N Jayasekara* ${ }^{3}$ D.A.C.L Dalugama, ${ }^{3}$ W.M.S.N.K Nawarathne, ${ }^{3}$ K.M.N.G.N Dias, ${ }^{3}$ S.D Dharmarathne. 'Brighton and Sussex University Hospitals, Brighton, UK; ${ }^{2}$ Faculty of Medicine, University of Sydney, Sydney, Australia; ${ }^{3}$ Faculty of Medicine, University of Peradeniya, Peradeniya, Sri Lanka

\subsection{6/sextrans-2016-052718.129}

Background People living with HIV/AIDS(PLWHA) are vulnerable to discrimination because of the stigma associated with the disease.

Aim(s)/objectives To examine the level of disease awareness, discriminatory attitudes towards PLWHA and factors in association with such attitudes.

Methods A cross sectional survey was conducted by using a semi-structured validated telephone questionnaire of a random sample from the Sri Lankan telephone directory. The questionnaire consisted questions regarding awareness of the modes of transmission and questions to assess the attitude toward PLWHA.

Results Around 92\% (120/130) of the respondents reported discriminatory attitudes in at least five out of the 20 relevant items, about 98\% would avoid making physical contact with PLWHA, hesitating to sit next in the public transport (98\%), divorcing the infected spouse $(85 \%)$ and dismissing a HIV positive maid $(100 \%)$. A sizeable proportion of the respondents exhibit negative perceptions; PLWHA are merely receiving the punishment they deserve (92\%) and believe that they are purposefully infect others (94\%). Also 89\% concluded that the majority of PLWHA are promiscuous. Multiple regression analysis found that age, HIV related knowledge, above mentioned negative perceptions about PLWHA and fear associated with AIDS are independent predictors of discriminatory attitudes towards PLWHA. About 90\% would give PLWHA the lowest priority in resource allocation among five groups of chronic diseases.

Conclusion Stigma among this study sample of general public was mostly due to fear of contracting the HIV/AIDS. Therefore, steps need to take increase public awareness and dissemination of information regarding HIV/AIDS to reduce the stigma associated with HIV.

\section{P076 THE CHARLIE SHEEN AFFAIR: HIV NARRATIVES IN THE UK MEDIA IN 2015 - DOES REPORTING MEET THE NATIONAL AIDS TRUST STANDARDS?}

${ }^{1}$ Craig McEwan, ${ }^{1}$ Rosie Briggs, ${ }^{1}$ Fionnuala Finnerty* ${ }^{1,2}$ Daniel Richardson. ${ }^{1}$ Brighton \& Sussex University Hospitals NHS Trust, Sussex, UK; ${ }^{2}$ Brighton \& Sussex Medical School, Sussex, UK

10.1136/sextrans-2016-052718.130
Background/introduction Despite media guidance from the National Aids Trust (NAT), there is evidence to suggest the UK media are continuing to portray HIV infection in a negative fashion. The "Charlie Sheen effect" has been described with a reported 400\% increase in Google related HIV searches just after Charlie Sheen's diagnosis.

Aim(s)/objectives Our aim was to identify themes of discussion about HIV in the media following the publication of Charlie Sheen's diagnosis, focussing specifically on language used.

Methods Articles were selected using the term "Charlie Sheen HIV" in Google search engine. Fourteen articles dating from 17th November 2015 to 27th November 2015 were reviewed and common themes identified. We compared the language used to NAT guidelines.

Results 9/14 articles were negative in their overall discussion about HIV and three contained factually incorrect information. There were a large number of sensationalist headlines and quotes including "HIV monster". 6/7 articles from 17th November referred to Sheen's drug use, wealth and sexual preferences. Three speculated about sexual contact with "prostitutes" and transgender men. Two articles commented on racism and domestic violence despite no association with article content.

Discussion/conclusion The media continue to associate HIV infection with negative personality traits, which have no impact on HIV transmission. The media has a key role in reducing stigma associated with HIV. With a quarter of people living with HIV in the UK unaware of their status, it is imperative that barriers to testing and treatment (including pervasive stigma) are tackled urgently.

\section{P077 MANAGING AN OUTBREAK OF INFECTIOUS SYPHILIS AMONG UNIVERSITY STUDENTS}

Gill Bell ${ }^{*}$, Helen Keegan, Sally Howlett. Sheffield teaching Hospitals NHS Foundation Trust, Sheffield, Yorkshire, UK

\subsection{6/sextrans-2016-052718.131}

Background/introduction In November 2015 we were surprised by 5 cases of infectious syphilis among university students, including two bisexual males and one female. Mindful of the potential for onward transmission bridging both homosexual and heterosexual networks in this atypical group, we alerted Public Health to a potential outbreak.

Aim(s)/objectives To report on management of an outbreak.

Methods A pre-existing Outbreak Control Team (OCT) liaised by telephone to discuss preliminary control strategies. Student Health services were alerted immediately by telephone and email. Partner notification (PN) for syphilis cases was prioritised and intensified: additional information was collected (descriptions, where/how met, where studying); provider referral was encouraged, and home visits undertaken to reach contacts before the Christmas vacation. Targeted screening and on-line health promotion via student bulletins and social network sites was introduced.

Results From November 2015 - January 2016, a linked network of 37 individuals was identified, of whom 29 (78\%) attended. Most contacts attended following provider referral (25/29; $86 \%)$. Repeated efforts were required to secure the attendance of several contacts. In all, 7 student cases of infectious syphilis were identified (1 female; 2 heterosexual males, 2 bisexual males, 2 MSM). The last 2 cases, identified in January, had initially tested negative 2-3 weeks after exposure. 
Conclusion A swift response, using a range of case finding and health promotion strategies successfully curtailed a nascent outbreak of infectious syphilis among university students. An intensive approach to PN, with an emphasis on provider referral, ensured the majority of partners attended with minimal delay.

\section{P078 CLOSING THE AUDIT CYCLE IN THE MANAGEMENT OF PELVIC INFLAMMATORY DISEASE (PID): UPDATING TRUST GUIDELINES LEADS TO A HUGE IMPROVEMENT IN PID TREATMENT}

Elizabeth Williams, Manori Bandara, Maryam Ahmad, Jake Bayley*, Liat Sarner. Barts Health NHS Trust, London, UK

\subsection{6/sextrans-2016-052718.132}

Background Correct management of Pelvic Inflammatory Disease (PID) is important to reduce complications but often varies widely. An audit of PID management in our trust's GUM clinics was undertaken in 2014 which led to trust guidelines being updated in early 2015. The main finding was antibiotic regimes were varied; only $12 \%$ received a BASHH recommended regime. We re-audited the management of PID in 2015.

Aim To compare PID management across our trust's GUM clinics in 2014 and 2015.

Methods Electronic patient records of 141 female patients with C5A codes in 2014 and 100 in 2015 were reviewed and compared.

Results In both audits 98\% of patients had Chlamydia/Gonorrhoea NAATs sent; 93\% had vaginal microscopy in 2014 and $92 \%$ in 2015 , but cervical microscopy improved from $13 \%$ in 2014 to $45 \%$ in 2015 . Pregnancy tests were inconsistently done, $83 \%$ in 2014 and $75 \%$ in 2015 . Those with chlamydia, gonorrhoea or trichomonas vaginalis increased from $8 \%$ to $13 \%$ but bacterial vaginosis was the most common finding, 28\% in 2014 and $46 \%$ in 2015. Antibiotic regimes were BASHH recommended in 12\% (2014) and 88\% (2015), due to updated 2015 trust guidelines being in line with BASHH.

Discussion Improvements have occurred since 2014 but cervical microscopy and pregnancy tests are still not consistently being done. Low levels of STIs detected may represent incorrect diagnosis in some. Antibiotic prescription has improved significantly, however we are still below the BASHH target of 95\% (currently $88 \%$ compliance). We will re-present findings of this re-audit to clinics to improve standardisation of PID management.

\section{P079 HIV SERVICES IN A CHANGING PROVIDER LANDSCAPE: PATIENT EXPERIENCES AND PERCEIVED NEEDS}

${ }^{1}$ Nalin Hettiarachchi ${ }^{*}$, ${ }^{1}$ Kurian Vithayathil, ${ }^{1}$ Duncan Leverton, ${ }^{1}$ Ruth Sim, ${ }^{1}$ John Beale, ${ }^{2}$ Usharani Natarajan, ${ }^{1}$ Shalini Andrews. ${ }^{1}$ Buryfields Clinic, Guildford, UK; ${ }^{2}$ Earnsdale Clinic, Redhill, UK

\subsection{6/sextrans-2016-052718.133}

Background/introduction With recent commissioning changes, non NHS providers are increasingly being awarded contracts to manage services including HIV care. There is little data on patient views and experiences around this change.

Aim(s)/objectives To obtain service user view of the aspects of the HIV service which they consider important in the landscape of commissioning changes.

Methods A patient survey was carried out in a community-based HIV service managed by a non-NHS provider. Questions were created to cover the most affected areas of the service due to the changes of HIV service provision.

Results A representative sample of 44 attenders over 2 months undertook the survey; 34 men and 10 women. All were satisfied with the service. However some expressed concerns since change of provider, such as "services are being stripped off", "not enough staff", "standards have fallen", "staff are under severe stress". The proportion that rated the following aspects of the service as very important or important to patients are as follows: 24hour on-call service (98\%), clinician access to investigation (95\%), HIV team involvement in teaching wider NHS (98\%) and current location (95\%), HIV team involvement in their inpatient care (98\%) and co-location of HIV and Sexual Health service $(100 \%)$. The majority $(86 \%)$ wanted an NHS provider, while $7 \%$ had no preference.

Discussion/conclusion The majority of patients preferred an NHS provider, with co-located Sexual Health services. They rated links with acute trust and the wider NHS as important aspects of their care. This needs to be considered while commissioning, planning and delivering future services.

\section{P080 AUDIT OF THE MANAGEMENT OF SEXUAL ASSAULT COMPLAINANTS ATTENDING GENITOURINARY MEDICINE AGAINST THE BRITISH ASSOCIATION FOR SEXUAL HEALTH AND HIV UK NATIONAL GUIDELINES ON THE MANAGEMENT OF ADULT AND ADOLESCENT COMPLAINANTS OF SEXUAL ASSAULT 2011}

${ }^{3}$ Hayley Colton, ${ }^{2}$ Gemma Carr, ${ }^{1}$ Anna Garner*. ${ }^{1}$ Stockport NHS Foundation Trust, Stockport, UK; ${ }^{2}$ The Rotherham NHS Foundation Trust, Rotherham, UK; ${ }^{3}$ Sheffield Teaching Hospitals NHS Foundation Trust, Sheffield, UK

\subsection{6/sextrans-2016-052718.134}

Background/introduction Patients attending clinic following an alleged sexual assault (SA) involve a complex history and management plan. The regional Sexual Assault Referral Centre (SARC) is on site and so the clinic receives significant numbers of SA referrals. As a clinic we felt that the proforma for documenting such histories was not fit for purpose.

Aim(s)/objectives To compare the documentation and management of SA complainants against standards set out by The British Association for Sexual Health and HIV UK National Guidelines on the Management of Adult and Adolescent Complainants of Sexual Assault 2011.

Methods A retrospective case note review of notes coded for SA between $1 / 1 / 13$ and $31 / 3 / 14$. 36 case notes were identified for inclusion.

Results 32/36 patients were female, 29/36 were heterosexual. 30/36 were of white British origin. 26/36 were referred from the local SARC. Age range 13-79 yrs. Areas which performed well in relation to the auditable outcomes were documentation in relation to: when the assault took place $(100 \%)$, child protection needs $(100 \%)$, who the assailant was $(94 \%)$, if baseline testing occurred (94\%), follow up advice (91\%), what type of assault (87\%). Areas which performed less well included documentation in relation to: bleeding at time of assault (8\%), physical injuries $(12.5 \%)$, ejaculation (24\%), self harm (16\%), mental state assessment (33\%).

Discussion/conclusion Documentation of a number of standards requires significant improvement. Safeguarding was well managed, particularly in those under 18. As a result of gaps in documentation a SA proforma has been devised to capture all the detailed information required when assessing SA patients. 